\title{
Little Helpers. About Demons, Angels and Other Servants
}

\section{Citation}

Canales, Jimena, and Markus Krajewski. 2012. Little helpers. About demons, angels, and other servants. Interdisciplinary Science Reviews 37(4): 314-331.

\section{Published Version}

doi:10.1179/0308018812Z.00000000025

\section{Permanent link}

http://nrs.harvard.edu/urn-3:HUL.InstRepos:10362023

\section{Terms of Use}

This article was downloaded from Harvard University's DASH repository, and is made available under the terms and conditions applicable to Open Access Policy Articles, as set forth at http:// nrs.harvard.edu/urn-3:HUL.InstRepos:dash.current.terms-of-use\#OAP

\section{Share Your Story}

The Harvard community has made this article openly available.

Please share how this access benefits you. Submit a story.

Accessibility 
Little Helpers. About Demons, Angels and Other Servants

Jimena Canales

Department of the History of Science, Harvard University, Cambridge, USA

Markus Krajewski

Faculty of Media, Bauhaus University, Weimar, Germany

\begin{abstract}
In politics as in history, masters accomplish great things, but often, lowly beings such as servants perform those tasks. At times, they subvert them. In science, servant-beings are frequently described as demons and angels. Who are these effective agents? This essay traces parts of the large historical network of persons and places in which 'little helpers' service their master's will. It looks at instances where masters try to exorcise the servant-demons who instead of helping them, disturb their plans. By uncovering fragments of this often hidden network, we explore the strange relationship between masters and servants, and the role of earthly and heavenly agents in science.
\end{abstract}

In 1821 Georg Conrad Horst, grand-ducal member of the Hessian ecclesiastical council, defined demons as 'the medium that produced phenomena acting against the usual order of things'. (Horst 1821) A century and a half later, demons were still busy at work, doing a fabulous job upsetting 'the usual order of things'. Their modus operandi and their secret hiding places had nonetheless changed considerably from the ones that Horst had previously discovered and exorcised. Demons in the age of technology, in the second half of the 20th century, were meaner and leaner. It was questionable that they carried any weight; it was questionable that they had any substance. Their manner of operating was no longer mechanical but informational. They no longer pushed and shoved, having taken refuge in a new environment where 'information replaces ordinary pushes and shoves' (Scully 2007, 138). In this study, we trace (at least parts of) the historical network in which demons performed their - often hidden and often menial - work. ${ }^{1}$

\title{
The long history of demons
}

The concept of demons is almost as old as occidental history. First citations are found in the Iliad. There, the term $\delta \alpha i ́ \mu \omega \nu$ designates both good and bad deities. Demons are often defined by practices of 'allotting' and 'assigning', along with those of 'differentiating', 'sorting' and 'ordering'. The main feature of a $\delta \alpha i ́ \mu \omega v$, 
however, is a being showing up 'in-between mortal and immortal', a medium between gods and mankind. A demon thus appears as a mediator between immanence and transcendence. Its core function encompasses establishing a communication channel between the human senses and another realm, which is much more removed from plausible human understanding. The demon establishes communication between explicable contexts on the one hand and spiritual phenomena on the other. Whereas Socrates as well as Plato mainly stressed the god's benevolent features such as protection, these mediators have acquired a rather ongoing negative connotation, as Plato's pupil Xenocrates assigned positive features only to 'real' deities. Since then, demons have had a bad reputation.

Not all demons are bad. On the contrary, where there is a demon there is usually an angel passing by. Demons are all about opportunity, about finding the place where the least force can produce the strongest effect. Their presence usually reveals Archimidean points where a simple operation (such as lifting a lever) can be used for great effect - to lift nothing less than the world. Demons place themselves at key points of delegation. Where these points lay varies according to different epochs. By WWI, the traditional seat of power-the king's throne-had been completely replaced by direct access to a telegraph network.

From the time of the French Revolution to the 21st century, the workplace of demons underwent significant transformations. During this period, two important demons stand out. The first demon is usually connected to the first industrial revolution, and the second demon is connected to the second.

In 1814, the demon described by the French mathematician and founder of probability, Pierre-Simon de Laplace, observed everything, knowing all the atomistic states of past and future elements and their laws. It could predict the future. 'An intellect which at any given moment knew all of the forces that animate nature and the mutual positions of the beings that compose it, if this intellect were vast enough to submit the data to analysis, could condense into a single formula the movement of the greatest bodies of the universe and that of the lightest atom; for such an intellect nothing could be uncertain and the future just like the past would be present before its eyes'. (Laplace 1951, 4)

Later in the century, the famous Scottish physicist James Clerk Maxwell described a different kind of entity that would become known as Maxwell's demon. Initially, Maxwell wrote about a 'very observant and neat fingered being' that despite its small proportions could wreak havoc on the laws of nature, particularly on the second law of thermodynamics, also known as the law of entropy. Maxwell did not define his little actor as a demon, but others around him soon did. He kept this little fellow free from supernatural features and described it in terms of basic qualities, such as well-defined mechanical and manual skills. Nevertheless, he assigned an ephemeral character to his creature at the same time he certified its ability to intervene in molecular 
processes. Maxwell's little being was invisible but present, an attentive agent lying in wait in order to serve, a simple creature free of transcendental high-altitude flight. Maxwell's contemporary colleagues such as William Thomson (a.k.a. Lord Kelvin) baptised the creature a demon, and from 1874 on, one can reconstruct a whole genealogy of attempts to exorcise this demon; an ongoing process until today (Leff and Rex 1990; 2003).

Maxwell first compared his 'finite being' to a humble 'pointsman on a railway', whose oversight of a network of tracks could easily cause dramatic effects. He also described it as a 'valve' that simply by virtue of changing from open to closed could cause important repercussions. The term 'demon' was later used by Thomson, who preferred to increase the abilities of the creature instead of reduce them, and to talk of 'an army of demons' instead of referring to just one of them: 'By operating selectively on individual atoms he can reverse the natural dissipation of energy, can cause one-half of a closed jar of air, or a bar of iron, to become glowingly hot and the other ice cold'. (Thomson 1879) This demon was 'endowed ideally with hands and fingers - two hands and ten fingers suffice - he can do as much for atoms as a pianoforte player can do for the keys of a piano - just a little more, he can push or pull each individual atom in any direction' (Ibid). Thomson described the demon as 'a being with no preternatural qualities, and differs from real living animals only in extreme smallness and agility. He can at pleasure stop, or strike, or push, or pull any single atom of matter, and so moderate its natural course of motion'.

Maxwell and Thomson used the demon to show that the second law of thermodynamics could have exceptions to it. An important consequence of this approach involved the question of free will. The demon, as they described it, preserved the full force of natural laws while allowing for free will.

Free-will and life itself seemed in blatant contradiction to the second law. Thomson excluded living beings from being subjected to this axiom. At first, he even excluded vegetative action and chemical action, distinguishing living creatures and dead matter by the former's possession of free will. He differed from diehard materialists (Helmholtz, du Bois Reymond, Huxley and Tyndall), who wanted to subject everything, even free will and life, to thermodynamic laws. The physicist Balfour Stewart in his textbook on the Conservation of Energy (1868) explained how the existence of life itself could appear as arising from the humble position of a telegraph operator: 'Life is not a bully, who swaggers out into the open universe, upsetting the laws of energy in all directions, but rather a consummate strategist, who sitting in his secret chamber, before his [telegraph] wires, directs the movement of a great army'. Most importantly, the significance of Maxwell's demon resided largely in its relation to perpetual motion machines. One of the consequences of the second law of thermodynamics was that it explained why perpetual machines could never be built. Since then scientists, philosophers, and the public at large use the law to explain why, in 
general, 'we can't get something out of nothing'. Demons explain exceptions to this general rule - moments of exuberance and gain without equivalent effort or expenditure.

The economic consequences of perpetual-motion machines have been highlighted since the notion was first introduced. Seat-of-the-pants moneyin-yourpocket talk informed scientists' understandings of the demon. The German physicist Hermann von Helmholtz described all attempts to circumvent the second law as futile efforts by 'cunning heads of all centuries. . .to fabricate money out of nothing. . . to be capable of producing gold' (Helmholtz 1995, 19). The physicist Marian Smoluchowski, in his important attempt to exorcise Maxwell's demon, related the idea of the perpetuum mobile to a 'perpetual source of income' (1912). When it was hinted that 'we seem to be getting something from nothing', the computer scientist Richard Laing answered bluntly: 'Such "free" computation offends our understanding about physical systems in general, as well as all practical experience of the properties of computing machinery'. (Laing 1974, 175) In 1984, W. H. Zurek of the Los Alamos National Laboratory, thought instead about the cost to the environment, concluding his paper on the demon with a moralistic warning: ' $[\mathrm{O}]$ ne can imagine that the ability to measure, and make the environment 'pay' the entropic cost of the measurement is also one of the essential attributes of animated beings'. (Zurek 1984, 161)

\section{Demons and parasites}

In December 1975, the French philosopher Michel Serres started to write a book about contemporary demons. Serres discovered that demons (employing their usual ability of working through others) were to be found in a variety of parasites which were no longer limited to biological kinds. Instead, he saw them operate in the form of disturbances that accompanied messages and hampered communication. Noise, the bête noir of information theorists, resulted from the work of these parasites.

To understand how parasites (noise) affected transmission and communication, Serres turned to the example of Maxwell's demon: 'Hermes is the god of the crossroads and is the god of whom Maxwell made a demon'. Despite Hermes's best efforts to keep the crossroads safe, to circumvent interception, he could not prevent from being at times parasite and at times subjected to parasitism, because 'the parasite has placed itself in the most profitable positions, at the intersection of relations'. In a similar way to the work of Maxwell's demon, the work of parasites constituted an exception to the usual order of things leading to a dramatic result: the inevitable inequality between people. 'How a very few people manage to enslave the greatest number - more or less all of humanity - that is the miracle and is the exception to every law', explained the philosopher. Serres, writing in the middle of the 1970s, pointed his finger at the exact place that produced these exceptions: 'the world empire of IBM'. (Serres 2007, 96) 
Understandings of Maxwell's demon changed with quantum information theory. For Serres, parasitology required thinking about the exchange of both 'energy and information' (169). According to quantum mechanics, even the most unobstrusive forms of observation left their mark: 'Photon bombardment' made 'complexity increase'. Serres drew from contemporary explanations of Maxwell's demon in terms of Brownian motion fluctuations and solid state, semiconductor, physics: 'Irreversible time begins with the parasitic noise, with fluctuations. .' Maxwell's demon was a 'valve' that behaved as a 'semiconductor' (187).

The ambition of Serres's demonological tract on parasites was vast. His concern was to find 'how a very few people manage to enslave the greatest number' (58). Questions of domination of the few by the many were frequently seen as reversals of thermodynamic forces of entropy - reversals that could only be accomplished by demons similar to the ones that Maxwell had described. The distribution of power in society was not reaching equilibrium. Although a hot body placed next to a cold one should cause a heat flow resulting in both bodies reaching an intermediate temperature, when it came to the flow of power in society, the result was inverse. The powerful were gaining more power while the weaker were losing it. As each day went by, the balance worsened.

Although their numbers could never be equal, the position between hosts and parasites was never fixed. Parasites changed positions so rapidly, where 'the parasited one parasites the parasite' making it impossible to eliminate them: 'Chase the parasite - he comes galloping back, accompanied, just like the demon of an exorcism, with a thousand like him, but more ferocious, hungrier, all bellowing, roaring clamouring'. Exorcism was not the solution; the only option was for a host to 'counter-parasite' the guests, turning the tables. For Serres, any change in roles was only a movement up or down the parasitical chain, the cascade. Victory was always relational: 'But the one in the last position wins this game'. Albeit momentarily, because 'the last position. . .is rather difficult to maintain' (45).

The arrow of time, our thermodynamic condition, the inevitable work of entropy, eventual dissipation and equilibrium was accompanied by an analogous effect leading toward disequilibrium where 'a very few people manage to enslave the greatest number'. This disequilibrium resulted from the work of parasites parasiting each other, occupying the role of host only momentarily to fall back again to the more numerous condition of parasites. The chain of parasitical relations, according to Serres, constituted the very fabric of temporal development: 'the relation denoted by a single arrow is irreversible'. Because of its irreversibility, parasitic chains were always unidirectional: 'The flow goes one way, never the other. I call this semiconduction, this valve, this single arrow, this relation without a reversal of direction, "parasitic."' (5)

In a universe 'where we eat at the expense of another', it was essential to study not only who ate whom but how information was used, diverted or distorted to 
facilitate this ultimate aim. Scientists, particularly information theorists, fought hard to control and use parasites, who always positioned themselves at places of potential interception, diverting everything from goods to messages in their favour: 'What passes might be a message, but parasites (static) prevent it from being heard, and sometimes from being sent', he warned. Information theorists were experts in one form of exorcism, that of eliminating noise: 'Eliminate the parasites from the channel so the message can go through as best it can' was their goal (56). During these years, other theorists like the philosopher Jean-François Lyotard joined Serres in underlining the new importance of information in contemporary society (Lyotard 1974). Serres's parasites knew that their power depended on information, not only on its creation but mainly its theft. Parasites' ultimate goal was 'to withdraw knowledge from the greatest number' to increase their power. 'Power', he explained baldly, was 'the balance beam between the loci in which information is stocked and those from which it is withdrawn' (Serres, 37).

Scientists often aspired to gain the position of angels, not only in terms of their sensorial abilities, but in terms of their role as messengers. When Galileo published his Siderius Nuncius, it was precisely this aspect of sending and receiving pure messages that he stressed. Classically, angels as messengers of God deliver unmanipulated information, although they do not usually narrate the message in direct prose. Demons, however, are under notorious suspicion of manipulating their messages. Both messengers have in common that they act as mediators between Heaven and Earth. Both establish a communication channel between the realm of immanent things and the other world which withdraws itself from experience. Within this scheme of communication, angels exclusively function in such a way that they carry messages without influencing the contents. Thomas Aquinas depicted angels as the mouthpiece of God. Patiently, they transmit information unaltered and undeformed. Demons act differently. They offer a specific force of production enabling them to manipulate information.

In 1964, the media theorist Marshall McLuhan described electric light as 'pure information', as a 'medium without a message' (McLuhan 1964, 8). But light was not as pure as McLuhan made it to be. Although McLuhan gave to 'electric light' the role classically taken by angels as message deliverers, quantum physicists stressed its distorting aspects. Serres explained how 'People always talk about the light that is indispensable for seeing and observing. Even Maxwell's demon needs this light' (236). In contrast to McLuhan, Serres stressed the violence of all technologies that allowed for seeing - even that of electric light, because of the photon bombardment which the demon required even to see. It was this aspect that the media theorist Friedrich Kittler criticised when he read McLuhan, especially because of its theological implications. Kittler pointed out that McLuhan 'converted to Catholicism long before his international career'. The German theorist criticised the 'arch-catholic media cult' 
developing around McLuhan. 'McLuhan', mocked Kittler, 'confuses the Holy Spirit and Turing's machine' (Kittler 2010, 30). The Holy Paraclete's impressive polyglot talents the sacred gift of communication and tongues - was not given for free, after all.

\section{Demons and servants}

The work of both parasites and demons was often menial: 'To work is to sort. Maxwell's demon is unavoidable, just like the parasite'. It lay always somewhere 'between the god and the servant'. The close semantics of demon and demonstrator, as the laboratory servant is called in the early Royal Society, is a first hint while pursuing the relationship between demons and (scientific) servants. Within the scenarios of Maxwell or Laplace, the demon systematically occupies the position which in real experimental arrangements are held by the laboratory servant. Despite of varying strategies in order to exorcise them, the demonic servants or serving demons remain an indispensable, albeit notoriously ignored, basic part of experimental arrangements. Thanks to their sometimes manual, sometimes mental work during experiments, they serve to stimulate new discoveries, being privileged creators of first-hand knowledge. As with demons, the role of laboratory assistants and scientific servants of all kinds are also systematically neglected in the annals of scientific historiography.

In the 1970s, computers started to be conceived as servants. Max V. Mathews, the father of computer music who worked at AT\&T Bell Labs, predicted how 'digital computers give promise of serving mankind as no other machine and no animal has ever done'. A decade earlier in 1960, Joseph Carl Licklider and Bob Taylor, visionaries of an online community mediated by computers and working at the Palo Alto Research Center (PARC), imagined a personal computer, named OLIVER, arguing that it was an 'on-line interactive vicarious expediter and responder'. An OLIVER was conceived as a servant for servants, one that 'acts on behalf of its principal, taking care of minor matters that do not require his personal attention and buffering from the demanding world. 'You are describing a secretary', you will say. But no! Secretaries will have OLIVERS' (Licklider 1960/1990, 38).

The servile tasks done by computers were described as being done by demons, who were now working inside computer systems. In 1963 Fernando J. Corbató, working at MIT with an IBM 7094, explained how his team started to 'fancifully... .use the word daemon to describe background processes which worked tirelessly to perform system chores'. The term referred to Maxwell's demon: 'Our use of the word daemon was inspired by the Maxwell's daemon of physics and thermodynamics', Corbató explained (Steinberg 2002).

When delivering his Clifford Paterson Lecture in 1979, Gordon George Scarrott made this change clear already in its title, 'From Computing Slave to Knowledgeable Servant'. He explained the shift: 'The original objective of computer design. . .was to devise a computing slave. . without the benefit of any consideration of the role of 
'information'. . or the consequential requirements for devices to assist people to handle their information'. Scarrott detailed the role of the servant in computing communication theory. While 'a slave simply obeys instructions. . .the good servant understands and respects his master well enough to respond constructively, even if his instructions are incomplete or internally inconsistent'. The servant's contribution to communication was essential: 'The good servant does this by understanding or even anticipating his master's wishes and using his own initiative to meet them'. (Scarrott 1979, 5ff.; 15f.) Since then, the word demon or daemon in computing continued to designate servile, clean-up background chores performed by computers, giving birth to the now pervasive MAILER-DAEMON. In the general sense, daemon is an older form of the word demon, from the Greek $\delta \alpha i ́ \mu \omega v$. In one of the so-called 'bibles' of computer handbooks, the Unix System Administration Handbook, the computing expert Evi Nemeth described theiruse of the term:

'Daemon' is actually a much older form of 'demon'; daemons have no particular bias towards good or evil, but rather serve to help define a person's character or personality. The ancient Greeks' concept of a 'personal daemon' was similar to the modern concept of a 'guardian angel' - eudaemonia is the state of being helped or protected by a kindly spirit.

'As a rule, UNIX systems seem to be infested with both daemons anddemons', she concluded (Nemeth 1989, 403).

\section{Information}

From the 1950s onward, most questions about how demons functioned centered on their role in the transfer of information. Scientists and philosophers across fields and disciplines asked if information was also subject to the law of thermodynamics. Thermodynamics clearly predicted unidirectional dissipation, decay, and heat-loss leading to an eventual equilibrium. Was the transfer and storage of information subject to the same effects as that of energy? If not, could information be used to mitigate, combat or even stunt the second law of thermodynamics? At the centre of these questions stood inquiries into the limits of knowledge, the power of computers, and the possibility of reaching social equilibrium. In all of these areas, demons, some good some bad, played important roles.

In 1929, the physicist Leo Szilard, known for conceiving the possibility of nuclear chain reactions a few years later, published an important exorcism of Maxwell's demon. In his paper, Szilard claimed that nothing was free - not even measurement. Yet in the years that followed demons once again emerged galloping and bellowing like never before, and in no small part in connection to Szilard's and others' work on atomic energy. It was clear that from the time when Szilard published his paper in 1929 to the late 1940s, scientists had radically changed their views about getting something from 
nothing. In particular, radioactivity, the atomic bomb, servomechanisms, and early computer systems led many to rethink questions of energy, information and knowledge.

While still working at the Cruft Laboratory at Harvard and preparing to move the International Business Machines Corporation (now known as IBM) as director, the mathematician, information theorist, and solid state physicist León Brillouin explained the limitations of the second law of thermodynamics, rethinking the role of Maxwell's demon. Brillouin believed in this almost sacred law, but he nonetheless insisted it was not 'strictly enforced', since it had clearly allowed for 'some sort of miracle' to take place: scientist's utilisation of uranium. 'Uranium remained stable and quiet for thousands of centuries; then came some scientists, who built a pile and a bomb and, like a naughty boy in the kitchen, blew up a whole city', he explained (Brillouin 1949, 560). At first, Brillouin did not attempt to create an alternative explanation of 'the paradox of Maxwell's demon' at the molecular level. He was satisfied to claim that, at least on the macroscopic human scale, violations to the second law were rampant. Although the demon had been sufficiently exorcised since Szilard published his paper and made it 'unthinkable' to think of a demon 'standing by a trapdoor and opening it only for fast molecules', the situation still seemed dramatically different on a macroscopic scale.

How do clear exceptions to the law of thermodynamics become feasible on a large scale, asked Brillouin? The physicist provided a quick answer: 'Man opens the window when the weather is hot and closes it on cold days!' (566) From these simple types of actions, important exceptions occurred: 'conditions forbidden on a small scale are permitted on a large one'. It was important, he argued, to focus on phenomena on the 'fringe of the second principle'. Neither uranium bombs nor 'large-scale computing machinery', (567) seemed to fit the nineteenth-century concepts of entropy nor the demons associated with it.

At the time that Brillouin was writing, the simple act of opening and closing windows had been outsourced yet one more time. After having been passed from the master to the servant in the bourgeois households of the nineteenth century, it had finally been delegated to the thermostat. Norbert Wiener, author of Cybernetics (1948) and one of the principal founders of the field, explained this little instrument's importance. 'The ordinary thermostat by which we regulate the heating of a house is', he explained, an example of 'a feedback chain in which no human element intervenes'. Like Brillouin, Wiener thought about Maxwell's demon in this context. Both accepted the second law of thermodynamics as well as pre-existing exorcisms of Maxwell's demon that made it standard knowledge that 'it is impossible to obtain any information. . . without a ... effect on the energy of the particle examined' (Wiener 1948/1965, 58). But both Wiener and Brillouin were nonetheless sure that the demon existed in certain situations. 'Nevertheless', Wiener cautioned, 'there may be a quite appreciable interval of time before the demon is deconditioned, and this time may be so 
prolonged that we may speak of the active phase of the demon as metastable' (Ibid). His conclusion, that is, his belief in demons, was clearly stated: 'There is no reason to suppose that metastable demons do not in fact exist'. (Ibid) In addition to the uranium and large-scale computing that bothered Brillouin, all these seemingly innocuous delegations to thermostats, governors, and servo-mechanisms of various kinds were leading top scientists to re-evaluate the place of demons in their midst. ${ }^{2}$

Brillouin, Wiener and many other scientists working in the post-war period understood and accepted Szilard's argument that in order to work, the demon needed to take a measurement, that this measurement was information about a given particle, and that obtaining that information required energy. Yet many of these scientists did not believe that there was an exact one-to-one correspondence in the expenditure of energy and the gain in information. Wiener put it plainly: 'Information is information, not matter or energy'. (Wiener 1948/1965, 132) Brillouin explained the same idea in different terms: 'Take an issue of the New York Times, the book on Cybernetics, and an equal weight of scrap paper. Do they have the same entropy? According to the usual physical definition, the answer is "yes."' (Brillouin 1949, 566) But answering yes, according to Brillouin, was an overly 'hasty conclusion'. For him, 'information value' could not be determined in the same manner as other physical values.

Philosophers of science weighed in on the matter. Sir Karl Popper always believed that there was something more to information and to knowledge that differentiated it from energy (Popper 1957). The philosopher Paul Feyerabend was uncharacteristically optimistic, thinking that knowledge could help mitigate the otherwise debilitating forces of entropy. He sided explicitly with Popper and Brillouin, concluding that the existence of these demons was 'in principle possible'. Rudolph Carnap (1977) was more cautious, acknowledging the need to think of the 'important relations between the two concepts' of entropy in information theory and thermodynamics (Carnap 1977).

Not everyone, however, believed that this poltergeist was all that pervasive or that the obtainment of information could lead to such simple violations of the second law. The physicist Richard Feynman in 1963 argued that after operating for a limited amount of time, 'the demon. . .must heat up'. 'Soon', he argued, 'it cannot tell whether it is coming or going, much less whether the molecules are coming or going, so it does not work' (Feynman et al. 1965, 5). The physicist Oliver Penrose in 1970 advanced a similar argument in terms of an increase in the need to store information, which would offset any gain from it (Penrose 1970).

Wiener's view that 'information was information' was increasingly dismantled. In 1986, working at IBM, Rolf Landauer, in his own exorcism of the demon, explained the new conception of information in the era of thepersonal computer: 'Information, numerical or otherwise, is not an abstraction, but is inevitable tied to a physical 
representation.... There is really no software, in the strict sense of disembodied information, but only inactive and relatively static hardware'. (Landauer 1987, 88) His message would be repeated by the media theorist Friedrich Kittler (1992). By 1970s the idea that information had a price had been refinedconsiderably, largely due to how it was reconceived in light of the concept of a 'bit' of information, a term that originally meant 'binary digit'. In 1948 Claude Shannon published his groundbreaking 'A mathematical theory of communication', using the word 'bit' (introduced by his colleague John Tukey) to define the smallest possible unit of information, which was 'true' or 'false', 'left' or 'right' 'up' or 'down' and could be coded in binary terms as 1 or 0 (Shannon 1948). His colleague at Bell Labs John R. Pierce reinterpreted the role of Maxwell's demon in relation to 'bits', attempting a renewed exorcism. Pierce argued that 'in order to know' what molecule to act on 'we need one bit of information, specifying which side the molecule is on' (Pierce 1961, 201). Researchers working at Bell labs increasingly defined information in terms of overcoming background noise. The minimum amount of the energy to overcome background noise was equivalent to a bit. The bit became the unit that related entropy in communication with entropy in thermodynamics (Ibid). ${ }^{3}$

As his predecessors, Pierce framed his result in terms of its economic consequences, arguing that 'the important thing is that even at the very best we could do more than break even' (202). But what is important to remember is that Pierce's work at Bell labs consisted in exorcising demons defined as noise and limiting their millennial mandate to distort information and upset the laws of nature. But demons proliferate whenever they are exorcised. Jack Morton, manager at Bell Labs where Pierce worked, explained his approach at running the corporation as one that 'emphasizes ... the 'Maxwell Demon' role of the manager' (Morton 1971, 122).

\section{The material culture of demons}

Every time an exorcism was attempted - from the moment the demon was baptised as Maxwell's - scientists thought about it in terms of their place among things that were prevalent in the specific environment of the time period where a specific author worked. For Maxwell, his concern was still largely steam engines. For Marian Smoluchowski, an expert in fluid mechanics, Brownian motion substances became important; For Szilard, in 1929, measurement was conceived simply in terms of a 'position of a pointer', which was a characteristic way of measuring from the middle of the nineteenth century to the first decades of the next; a decade later the demon nearly always carried a 'torchlight' or 'flashlight' in order to see. This simple accoutrement reflected quantum mechanical theories of black body radiation and of photon bombardment and the inability to have pure observations that did not influence the object under observation. In 1949, Wiener included photoelectric cells, black body 
radiation, enzymes and a torch light; In 1961, Landauer of IBM thought about it in terms of magnetic core memory. Two years later, Feynman included 'electrical rectifiers'. The following year, Dennis Gabor (who would win the Nobel Prize in Physics in 1971) introduced incandescent lamps, mirrors and photodetectors. Penrose in 1970 thought about the demon in terms of memory capacity and storage; For Laing (1974), it was a computing automaton, and for others at the time it was a robot. In 1973, Bennett thought about it in terms of magnetic tape and RNA polymerase replication. In 1980 Alvin M. Weinberg, who was a director of the Oak Ridge National Laboratory and later headed its Institute for Energy Analysis, dealt with microprocessor controls on internal combustion engines.

These scientists lived in different historical eras with characteristic concerns. In his study on Maxwell's demon, for example, Weinberg mentioned the importance of the '17 million barrels of oil that flowed each day through the Straits of Hormuz before the Iran-Iraq war' (Weinberg 1982, 49). When in 1986 Landauer explained the relation between the entropy of information and that of energy, he claimed that 'the handling of information is inevitably tied to the physical universe, its contest and its laws' - quite specifically reflecting the IBM environment under which he worked (Landauer 1987, $88)$.

Any attempt to retrospectively judge the validity of each approach is defeated by the radical changes in the demon's environment, where we would not only be comparing apples and oranges, but valves and semiconductors. But a long view of demons also reveals one outstanding constant: demons' work is both menial and unappreciated yet it produces dramatic effects. For Charles Bennett the real devil was in the 'cleanup' constantly performed by efficient computing systems (Bennett 1982, 922). From Loyola's cloister to the black box

Increasingly, a number of scientists believed that understandings of physical problems in terms of the behaviour of molecules in perfectly closed isolated systems missed some of the essential complexities of the world of entropy. While the examples of perfect containers could be useful for older thermodynamic understandings of entropy, they were grossly inadequate for understanding it in terms of information transfer and communication.

By the late 1940s, most scientists understood information transfer in terms of black body radiation, that is in terms of the minimum amount of energy that overcomes the radiation of systems in equilibrium at a certain temperature. Brillouin explained the new predicament faced by the demon: 'In order to choose the fast molecules, the demon should be able to see them; but he is in an enclosure in equilibrium at constant temperature, where radiation must be that of the black body, and it is impossible to see anything in the interior of a black body'. (Brillouin 1949, 565) The science of black body radiation explained what happened in insulated containers in a new way. A quantum of radiation energy could never be completely sealed off from these enclosures. 
At the Mental Research Institute in Palo Alto (MRI), scientists argued for the need to completely overhaul the traditional way of thinking about both Laplace's and Maxwell's demons in light of this new research. In a book dedicated to the cyberneticist Gregory Bateson, they argued for scientists to abandon 'the mechanistic world-view [that] found its ideal in the Laplacean spirit, i.e. in the conception that all phenomena are ultimately aggregates of ... actions of elementary physical units' (Watzlawick et al. $1967,124)$. Second, they insisted that all 'methods of analysis appropriate to things which can be reasonably put in 'a sealed insulated container' were significantly obstructive and misleading' (122). What, then, did MRI scientists consider as more appropriate models for understanding the world, our place within it, and demons?

At MRI, the concept of a 'black box', borrowed from 'the field of telecommunication' was particularly useful. Although the concept was 'applied originally to certain types of captured enemy electronic equipment that could not be opened', (43) it had immediate relevance to their research and philosophical outlook. The main difference with the Laplacean mechanistic view was that black boxes incorporated input, output and feedback, changing in a way that could not be entirely predicted beforehand. Another difference with Maxwellian sealed container examples was that in black boxes outside disturbances or noise were managed rather than eliminated. Unlike the tabernacle (or its smaller pyx version) that protected the Eucharist from contamination, black boxes showed that nothing could ever be perfectly isolated from the outside.

Sensory deprivation experiments, in which subjects were placed in silent, isolated and confined chambers, led scientists to this conclusion: 'All these facts, incidentally, from the disturbances of the sensorium to the problem of self-awareness, are borne out by the now extensive literature on sensory deprivation'. (28) Sensory deprivation experiments had revealed a surprising result. Three Canadian researchers noticed that hallucination effects similar to those caused by overstimulation also appeared under sensory deprivation (Bexton et al. 1954). Visions surfaced even when subjects were placed in completely insulated chambers.

The history of sensory deprivation experiments can be traced back to the solitary cloister cell experiments (spiritual exercises) of Iñaki Lopez, better known as Ignatius de Loyola, founder of the Jesuit order. Jesuit spiritual exercises required isolation in a solitary cloistered cell - isolation kept both demons and temptation out, leading the subject in solitude confronting an emergent production of holy visions and religious spectacles. Loyola, as a principal soldier of the counter-reformation and in direct competition to its burgeoning (boring) print culture, became particularly successful in extending these private exercises to a broader public. Jesuit theatre extended these cell experiments by setting on stage religious visions of heaven and hell which previously had only appeared in the imagination of a single participant. These theatrical productions thrived on a particular innovation: the trapdoor. Although theatres were 
closed and dark, a small trapdoor on the floor permitted the rapid entrance and exit of demons to the stage. Carrying hot and smoking torches and lanterns, they demonstrated hell to a growing public. Within these reformed (or more precisely, counter-reformed) black boxes, burning flames appeared as light sources that for the first time, enticed spectators into night-time entertainment venues. Centuries later, essential aspects of this concept remained unchanged: heat or cold, photons or information, could only enter or exit sealed containers through a door controlled by Maxwell's demon (Siegert 2012). Although the demon at first held a torchlight, in the era of Quantum Mechanics, the torch was replaced by a flashlight.

Sensory deprivation experiments were connected to a new theory of communication where it was no longer defined in terms of noise elimination, but where noise was productive. The difference between noise and information, argued Serres, lay in a 'hair's breath'. Serres learned this lesson from the everyday practice of tuning in to mass media technologies such as radio and television. 'Moving a hair's breath in either direction causes the noises to become messages', he explained (Serres, 67). Many philosophers of the period reached similar conclusions. For Gregory Bateson and Niklas Luhmann noise was an essential part of information - so productive that it even created humans as subjects. 'Language speaks us', insisted Luhmann.

Social stimulus deprivation experiments brought new lessons to current understandings of Laplace's spirit and Maxwell's demon. MRI researches did not tire to point out that 'one cannot not communicate'. New social settings that increasingly placed strangers together in confined quarters, intensified this lesson:

The man at a crowded lunch counter who looks straight ahead, or the airplane passenger who sits with his eyes closed, are both communicating that they do not want to speak to anybody or be spoken to, and their neighbours usually 'get the message' and respond appropriately by leaving them alone. (Watzlawick et al., 49) In 1962 at the Western Psychological Conference Convention held in San Francisco, the psychologist and therapist Joseph Luft presented a paper on 'social stimulus deprivation' as a 1960s contribution to the physical sensory deprivation experiments of the 1950s. His setup involved placing 'two strangers in a room' and seeing what happened. These controlled experiments had a host of natural experimental counterparts characteristic of their California context: sitting alone in a restaurant counter or flying to get there were prime examples, but they exemplified the growing experience of close encounters between strangers next to each other in closed spaces. MRI researchers explained: 'A typical situation of this kind is the meeting of two strangers, one of whom wants to make conversation and the other does not, e.g., two airplane passengers sitting next to each other. Let passenger $A$ be the one who does not want to talk. There are two things he cannot do: he cannot physically leave the field, and he cannot not communicate'. (Ibid) 
According to these new communication theories, effective communication was no longer about noise elimination. Serres described how ultimate power lay in owning the 'source and emission of sound'. Noise was useful to 'prevent others from saying'. Words and their meaning were not essential components of communication: 'The one who has the strongest and loudest voice is always right'. (Serres, 141)

The conclusion of sensory deprivation experiments led many scientists to argue that it was simply impossible to ever conceive of a perfect 'outside' representing a privileged position. MRI researchers cited the work of Wolfgang Wieser, author of Organismen, Strukturen, Maschinen (1959), to argue that because 'there exists no scientific language sophisticated enough to be the vehicle for their explanation', 'the systems themselves' were their own 'simplest explanation' (Watzlawick et al., 32). Palo Alto MRI researchers were happy to stop exorcising, preferring instead to acknowledge and live with the demons in their midst.

\section{The scientist as devil}

In 1975, Bruno Latour, a young Fulbright Fellow sent from Paris to study how scientific work was done at the Salk Institute of San Diego, noticed that scientists' everyday tasks paralleled those of the demon and that their results did as well. Inside the 'enclosure' known as the laboratory, scientists were successful at creating order from disorder. When attempting to 'become part of a laboratory', he described his job (writing in the third person) as one of becoming a demon: 'Like any conscientious Maxwell's devil, he filtered the names he required, counted the citations and inscribed them in columns'. (Salk 1986, 12) In light of Brillouin's and others' work on the demon, Latour found that the explanation fitted the laboratory like a glove to a hand: 'Maxwell's demon provides a useful metaphor for laboratory activity because it shows both that order is created and that this order in no way pre-exists the demons manipulations'. (Ibid, 45) Since the 1950s Brillouin had made that comparison himself: 'The physicist in his laboratory is no better off than the demon', he explained (Brillouin 1951, 336). Recently, in the journal of statistical physics, Marcelo Magnasco and Gustavo Stolovitsky returned to a similar idea, concluding: 'We are, in a sense, made of demons'. (Magnasco and Stolovitsky 1998)

In later work, Latour was no longer sure that the scientist was the devil, wondering if perhaps the devil was hiding somewhere else in the laboratory. Laboratory inscription devices were its most likely hiding place: 'Print plays the same role as Maxwell's Demon'. Print demons positioned themselves as file handlers: 'In our cultures 'paper shuffling' is the source of an essential power. . .that constantly escapes attention'. Minute changes in the direction of paper shuffling were the reason why 'the few may dominate the many' (Latour 1990). Demons long-acknowledged role as handlers of information explained it all very simply: 'no new theory, worldview, or spirit is necessary to explain capitalism, the reformation and science'. (Ibid) 


\section{Do demons make history?}

In the second half of the 20th century, most researchers had come to a radical assessment of who made history. Their radical conclusions had nonetheless important precedents. In 1758, Adrien Richer published his Essai sur les grands évenements par les petites causes. Similarly, Voltaire argued that the devastation of Europe in the Seven Years Wars resulted from the amour propre of two or at most three persons. The belief that a single man could make history appeared strongest in the era of Napoleon. In 1848, Marx introduced important qualifications to the idea that men made history when he explained that although they did make it, they did not make it as they willed, introducing the question of the 'make-ability' of history.

Tolstoy, writing in 1869 about the 1812 battle of the Russians against Napoleon, was no longer sure about who was responsible for victory. Bismarck himself felt less influential than others took him to be, arguing that 'my influence over the events in which I have been involved is indeed substantially overestimated' and adding that 'certainly no one should expect of me that I make history' (Bismarck 1968, 330). In 1903 Henry Adams thought that the demon's powers were greater than the ones that were allegedly running the nation: 'Clerk Maxwell's demon who runs the second law of Thermodynamics ought to be made President', he wrote to his brother Brooks (as cited by Carter 1947, 545, note 2).

For Serres, parasites - who know so well how to partake at a feast without payback - were the main actors behind historical development: 'History is full of them, or maybe is made solely of them', he ventured (Serres 2007, 5). It was not easy to determine who these actors were, especially because, like in the example of Maxwell's demon, micro-actors could cause macroscopic results. The devil is often in the details. With the example of Maxwell's demon the problem of agency entered with full force into the history of science: 'We do not know who are the agents who make up our world. We must begin with this uncertainty if we are to understand how, little by little, the agents defined one another, summoning other agents and attributing to them intentions and strategies' (Latour 1988, 35).

\section{Conclusion}

In this study, we have outlined a network of direct references that trace the often hidden work of demons as the little helpers of scientific work. In a way, the production of science seems to be a form of exorcism, because demons seldom perform tasks on their own without their masters. Yes, scientific work is an effort to distinguish art from artefact, but let us be frank in acknowledging that it is those little poltergeists who are experts in converting one into the other. ${ }^{4}$ Yes, scientific work is also about distinguishing noise from nature, but let us not forget that it is these restless beings' actual job description to distort information (Geimer 2000). Scientists band together in 
the fight against disturbances, contamination and waste, but do not forget that hordes of demons are always at work to subvert their efforts (Hoffmann 2001; Hoffmann and Schickore 2001). But most importantly, we must acknowledge that scientists themselves share some of the same interest of demons, especially in their aim to use knowledge to fight decay, dissipation and loss (of information) and to find those Archimidean points ideal for growth, gain and for obtaining the greatest effect with the least effort. But why have the role of demons in science been systematically relegated? Why have they

escaped attention at the same time that references to them abound? ${ }^{5}$ Perhaps because it is always easier to exorcise others than ourselves.

Scientists' work as exorcists is related to the philosophers' of science work in exegesis. As we mentioned before, demons come galloping back when they are exorcised. Exegesis, on the other hand, mitigates their power by helping us understand them. Latour eventually clarified his role as a philosopher of science: 'I deal with scientific wars by using resources offered by an exegesis of scientific texts. My "Tractatus Scientifico-Politico", instead of clearly dividing science from the rest of society, reason from force, makes no a priori distinction among the various allies that are summoned in time of war'. (Latour 1988, 7) He was simply doing for the twentiethcentury Science Wars what Spinoza had done for the seventeenth-century Wars of Religion. Spinoza's Tractatus Theologico-Politicus (published around 1665) had inaugurated the critical-historical reading of the Bible, but now a parallel reading of scientific texts was required (see Frampton 2006).

For more than a century and a half, explanations of Maxwell's demons have been attempted from the bottom up. By tracing his influence on the paths of tiniest molecules, scientists come to conclusions that range from predictingwhat the economy will do next to when the world will actually end. Here, we have attempted the opposite, to descend back from heaven to earth. What happens, for example, if we place scientist's seat-of-the-pants beliefs about basic moralistic truths (such as their frequently stated assumption that it is impossible to get something from nothing) at the basis of their subsequent knowledge about energy, information and entropy? Our goal is not to give an inverted image of authoritative knowledge - which was what Marx criticised more than a century ago when he claimed that 'in direct contrast to German philosophy which descends from heaven to earth, here we ascend from earth to heaven'. Our goal is to study heaven on earth (in this case, by focusing on substantial, material demons), and thus abandon the role played by historians, scientists and philosophers in exorcising the demons of modernity. ${ }^{6}$

Notes

${ }^{1}$ For our previous work on the topic see Canales, Jimena. 2008. Introduction. In The Matter of Fact: Exhibition Catalog. Harvard Collection of Historical Scientific Instruments, 
3; Canales, Jimena. 2012. Cleopatra's Nose-and the Development of World History. In Uncomfortable Objects, ed. Mariana Castillo Deball. Berlin: Bom Dia and Krajewski, Markus. 2008. Die Dämonen. Über Gehilfen in den Wissenschaften. In Archiv für Mediengeschichte 8: 39-51.

${ }^{2}$ Following Walter Benjamin, we can analyze these innocuous delegations as processes of involuntary acculturation, see Berlin Childhood around 1900. For a history of servomechanisms, see Mindell, David A. 2002. Between Human and Machine: Feedback, Control, and Computing before Cybernetics, Johns Hopkins studies in the history of technology. Baltimore: The Johns Hopkins University Press.

3 "The bit which measures amount of information used is the unit in terms of which the entropy of a message source is measured in communication theory. The entropy of thermodynamics determines what part of existing thermal energy can be turned into mechanical work. It seems natural to try to relate the entropy of thermodynamics and statistical mechanics with the entropy of communication theory." Ibid.

${ }^{4}$ For a study of how the distinction between art and artifact is drawn in scientific laboratories see Lynch, Michael. 1985. Art and Artifact in Laboratory Science: A Study of Shop Work and Shop Talk in a Research Laboratory, Studies in Ethnomethodology. London;Boston: Routledge \& Kegan Paul.

${ }^{5}$ An important exception is Schweber 1981.

6 "If in all ideology men and their circumstances appear upside-down as in a camera obscura, this phenomenon arises just as much from their historical life-process as the inversion of objects on the retina does from their physical life-process. In direct contrast to German philosophy which descends from heaven to earth, here we ascend from earth to heaven." Karl Marx, Karl and Friedrich Engels. 1969. The German Ideology. Parts $1 \mathcal{E}$ 3. Ed. with an introd. by R. Pascal. New York. Internat. Publishing.

Bibliography

Bennett, Charles H. 1982. The thermodynamics of computation - a review. International Journal of Theoretical Physics 21(12): 922.

Bexton, W. H., W. Heron and T. H. Scott. 1954. Effects of decreased variation in the sensory environment. Canadian Journal of Psychology 8: 70-76.

Bismarck, Otto von. 1968. Die Reichsgründung. Vol. 4 of Werke in Auswahl, ed. Eberhard Scheler. Darmstadt: Wiss. Buchgesellschaft.

Brillouin, Léon. 1949. Life, thermodynamics, and cybernetics. American Scientist 37: 55468.

Brillouin, Léon. 1951. Maxwell's demon cannot operate: information and entropy. I. Journal of Applied Physics 22: 334-37.

Carnap, Rudolf. 1977. Two essays on entropy. Berkeley: University of California Press. 
Carter, H. D. 1947. Henry Adams and his friends. A collection of his unpublished lett ers. Boston: Houghton Mifflin.

Earman, John and John D. Norton. 1998. EXORCIST XIV: The wrath of Maxwell's demon. Part I. From Maxwell to Szilard. Studies in History and Philosophy of Modern Physics 29 (4): 435-471.

Earman, John and John D. Norton. 1999. EXORCIST XIV: The wrath of Maxwell's demon. Part II. From Szilard to Landauer and beyond. Studies in History and Philosophy of Modern Physics 30 (1): 1-40.

Feynman, Richard Phillips, Robert B. Leighton and Matthew L. Sands. 1965. Lectures on physics, vol. 1, chapter 46. Boston: Addison-Wesley.

Frampton, Travis L. 2006. Spinoza and the rise of historical criticism of the Bible. New York: Clark.

Geimer, Peter. 2000. Noise or nature? Photography of the invisible around 1900. Shifting boundaries of the real: making the invisible visible, ed. Helga Nowotny and Martina Weiss, 119-35. Zürich: AG an der ETH.

Helmholtz, Hermann von. 1995. On the interaction of natural forces. Science and culture: popular and philosophical essays, ed. David Cahan, 18-45. Chicago: The University of Chicago Press.

Hoffmann, Christoph and Jutta Schickore. 2001. Secondary matters: on disturbances, contaminations, and waste as objects of research. Perspectives on Science 9: 123-25. Hoffmann, Christoph. 2001. The design of disturbance: physics institutes and physics research in Germany, 1870-1910. Perspectives on Science 9 (2): 173-95.

Horst, Georg Conrad. 1821. Zauber-Bibliothek. Oder von Zauberei, Theurgie und Mantik, Zauberern, Hexen und Hexenprocessen, Dämonen, Gespenstern und Geistererscheinungen. Zur Beförderung einer rein-geschichtlichen, von Aberglauben und Unglauben freien Beurtheilung dieser Gegenstände. Vol. 1. Mainz: Florian Kupferberg.

Kittler, Friedrich. 1992. There is no soft ware. Stanford Literature Review 9 (1): 81-90.

Kittler, Friedrich. 2010. Optical media. Berlin lectures 1999. Cambridge: Polity Press, 30. Krajewski, Markus. The servant. Media history of a figure between king and client.

Providence, Rhode Island: Yale University Press (in preparation).

Laing, Richard. 1974. Maxwell Demon and Computation. Philosophy of Science 41: 171178.

Landauer, Rolf. 1987. Computation: a fundamental physical view. Physica Scripta 35: 8895.

Laplace, Pierre Simon de. 1951. A philosophical essay on probabilities. Translated into English from the original French 6th ed. by F. W. Truscott and F. L. Emory. New York: Dover Publications.

Latour, Bruno and Steve Woolgar. 1986. Laboratory life: the construction of scientifi c facts. Princeton, N.J.: Princeton University Press. 
Latour, Bruno. 1988. The Pasteurization of France. Translated by Alan Sheridan and John Law. Cambridge, Mass.: Harvard University Press.

Latour, Bruno. 1990. Drawing things together. Representation in scientifi c practice, 19-68. Cambridge, Mass.: MIT Press.

Leff, Harvey S. and Andrew F. Rex (Eds.). 1990. Maxwell's demon. Entropy, information, computing. Bristol: Adam Hilger.

Leff, Harvey S. and Andrew F. Rex (Eds.). 2003. Maxwell's demon 2. Entropy, classical and quantum information, computing. 2nd edition. Bristol et al.: Institute of Physics

Publications.

Licklider, Joseph Carl Robnett and Robert W. Taylor. 1960/1990. The computer as a communication device. In memoriam: J. C. R. Licklider 1915-1990, ed. Robert W. Taylor, 21-41. Palo Alto: System Research Center.

Lynch, Michael. 1985. Art and artifact in laboratory science: a study of shop work and shop talk in a research laboratory. Studies in ethnomethodology. London and Boston: Routledge \& Kegan Paul.

Lyotard, Jean-François. 1984. The postmodern condition: a report on knowledge. University of Minnesota Press: Minneapolis. Originally published in 1979.

Magnasco, Marcelo O. and Gustavo Stolovitzky. 1998. Feynman's Ratchet and Pawl. Journal of Statistical Physics 93 (3/4): 615-32.

McLuhan, Marshall. 1964. Understanding media. The extensions of man. New York: McGraw-Hill.

Mindell, David A. 2002. Between human and machine: feedback, control, and computing before cybernetics, Johns Hopkins studies in the history of technology. Baltimore: The Johns Hopkins University Press.

Morton, J. A. 1971. Organizing for innovation: a systems approach to technical management. New York: McGraw-Hill Book Company.

Nemeth, Evi et al. 1989. Unix system administration handbook. New York: Prentice Hall. Penrose, Oliver. 1970. Foundations of statistical mechanics: a deductive treatment. Oxford: Pergamon Press.

Pierce, John Robinson. 1961. Symbols, signals, nnd Noise: the nature and process of communication. 1st edition, Harper Modern Science Series. New York: Harper. Popper, Karl. 1957. Irreversibility; or, entropy since 1905. British Journal for Philosophy of Science 8: 15155. Salk, Jonas. 1986. Introduction. Laboratory life: the construction of scientifi c facts, ed. Bruno Latour and Steve Woolgar. Princeton, N.J.: Princeton University Press. Scarrott, G. G. 1979. The Clifford Paterson Lecture: from computing slave to knowledgeable servant: the evolution of computers. Proceedings of the Royal Society of London. Series A, Mathematical and Physical Sciences 369(1736): 1-30.

Schweber, Silvan S. 1981. Demons, angels and probability: some aspects of British science in the nineteenth century. Physics as natural philosophy: essays in honor of Laszlo 
Tisza on his seventy-fifth birthday, ed. Abner Shimony and Herman Feshbach, 319-363. Cambridge, Mass.: MIT Press.

Scully, Robert J. 2007. The demon and the quantum: from the Pythagorean mystics to Maxwell's demon and quantum mystery. Weinheim: Wiley-VCH.

Serres, Michel. 2007. The parasite. University of Minnesota Press: Minneapolis. Originally published in 1980.

Shannon, Claude E. 1948. A mathematical theory of communication. Bell System Technical Journal 27(3): 379-423.

Siegert, Bernhard. 2012. Doors: on the materiality of the symbolic. Grey Room 47: 6-23. Smoluchowski, M.V. (1912) Experimentell nachweisbare, der üblichen Thermodynamik widersprechende. Molekular-phänomene, Physik. Z., 13: 1069-1080. Steinberg, Richard. 2002. The origin of the word daemon. History of Computing, Department of Computer Science at Virginia Tech. htt p://ei.cs.vt.edu/ history/Daemon.html (20/8/2007). Thomson, William. 1879. The sorting demon of Maxwell. Proceeding of the Royal Institution 9: 113-14. Watzlawick, Paul, Janet Helmick Beavin and Don D. Jackson. 1967. Pragmatics of human communication: a study of interactional patterns, pathologies, and paradoxes. New York: Norton. Weinberg, A. M. 1982. On the relation between information and energy systems: a family of Maxwell's demons. Interdisciplinary Science Review 7: 47-52. Wiener, Norbert. 1948/1965. Cybernetics: or, control and communication in the animal and the machine. 2nd edition. Cambridge, Mass.: Technology Press. Zurek, W. H. 1984. Maxwell's demon, Szilard's engine, and quantum measurements. Frontiers of nonequilibrium statistical physics, ed. G. T. Moore and M. O. Scully, 151-161. New York: Plenum Press.

Notes on contributors Jimena Canales is Associate Professor at the History of Science department at Harvard University. Specializing in the history of physics and astronomy, contemporary cultural theory, visual studies of science, and theories of modernity and postmodernity, she holds degrees in history of science (PhD, 2003; MA, 1997) from Harvard University and in physics and engineering (BS, 1995) from ITESM, Mexico. She is the author of $A$ Tenth of a Second: A History (University of Chicago Press, 2010). Additional publications include: "Of Twins and Time," In Neutrality in Twentieth-Century Europe, Lettevall, Somsen, Widmalm eds. (Routledge Press: 2012); "Desired Machines" Science in Context 24 (2011), pp. 329-359. “'A Number of Scenes in a Badly Cut Film' In Histories of Scientific Observation, ed. Daston and Lunbeck (University of Chicago Press, 2011). "Movement before Cinematography," Journal of Visual Culture, 5 (2006): 275-294; "Einstein, Bergson, and the Experiment that Failed," Modern Language Notes, 120 (2005): 1168-1191; “Criminal Skins," Architectural History 48 (2005): 235-256; and "Photogenic Venus," Isis 93 (2002): 585-613. 
Correspondence to: Jimena Canales, Harvard University, Department of the History of Science, Science Center 371, Cambridge, MA 02138, USA. E-mail:

canales@fas.harvard.edu

Markus Krajewski is Associate Professor of Media History at the Faculty of Media at Bauhaus University Weimar. During the academic year 2008/09 he has been a fellow at the Humanities Center at Harvard University where he also taught as a Visiting Professor at the Department of the History of Science. He is author of Paper machines. About cards \& catalogs, 1548-1929 (The MIT Press, 2011), Der Diener. Mediengeschichte einer Figur zwischen König und Klient (S. Fischer, 2010) [The servant. media history of a figure between king and client, Yale University Press, 2014], and of Restlosigkeit: Weltprojekte um 1900 (S. Fischer, 2006) [As for the rest. World projects and notions of globality around 1900, University of Minnesota Press, 2013, forthcoming], as well as editor of Projectors. Knowledge production in the pre-form of failure (Kulturverlag Kadmos, 2005). His current research projects include an epistemology of the peripheral, digital humanities, and the history of exactitude in scholarly and scientific contexts. He is also developer and maintainer of the bibliography software synapsen - a hypertextual card index (www.verzetteln.de/synapsen). For further information see: www.uniweimar.de/medien/wissenschaftsgeschichte.

Correspondence to: Markus Krajewski, Bauhaus University, Faculty of Media, Bauhausstr. 11, D-99423 Weimar, Germany. E-mail: markus.krajewski@uni-weimar.de. 